\title{
Erratum to: pulp bleeding color is an indicator of clinical and histohematologic status of primary teeth
}

\author{
Naser Asl Aminabadi ${ }^{1}$ - Marziyeh Parto $^{1} \cdot$ Parya Emamverdizadeh $^{2} \cdot$ Zahra Jamali $^{3}$. \\ Sajjad Shirazi ${ }^{4,5}$
}

Published online: 7 April 2017

(C) Springer-Verlag Berlin Heidelberg 2017

\section{Erratum to: Clinical Oral Investigations}

\section{DOI 10.1007/s00784-017-2098-y}

The name Naser Asl Aaminabadi in the original version of this article should be Naser Asl Aminabadi. Also, the equation found in page 3 of the original published article should be:

$$
\Delta \mathrm{E}_{\mathrm{ab}}{ }^{*}\left(\mathrm{~L}^{*} \mathrm{a}^{*} \mathrm{~b}^{*}\right)=\left[\left(\Delta \mathrm{L}^{*}\right)^{2}+\left(\Delta \mathrm{a}^{*}\right)^{2}+\left(\Delta \mathrm{b}^{*}\right)^{2}\right]^{1 / 2} \text {. }
$$

The online version of the original article can be found at http://dx. doi.org/10.1007/s00784-017-2098-y

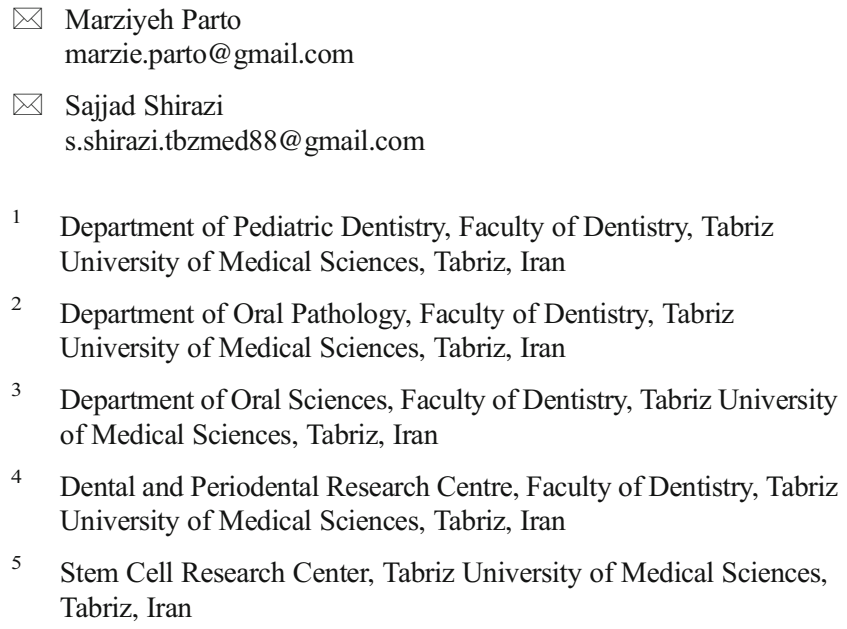

3 Department of Oral Sciences, Faculty of Dentistry, Tabriz University of Medical Sciences, Tabriz, Iran

4 Dental and Periodental Research Centre, Faculty of Dentistry, Tabriz University of Medical Sciences, Tabriz, Iran

5 Stem Cell Research Center, Tabriz University of Medical Sciences, Tabriz, Iran 